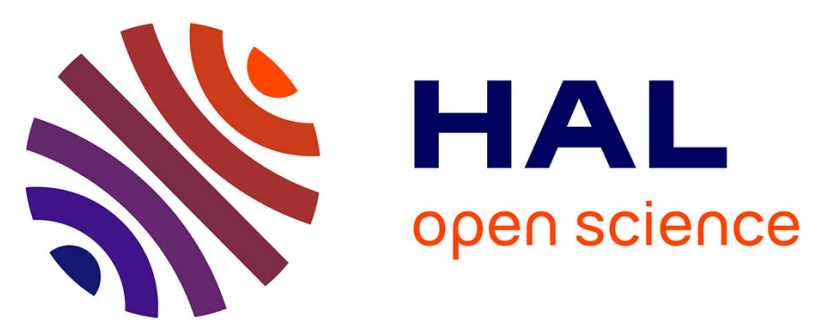

\title{
Fathers and Male Guardians Are Important Stakeholders in Children's Education: Do Lego Building and Scratch-like Programming Activities Hold a Key to Involving Them More?
}

Don Passey, Gavin Hawkins, Darren Clift

\section{To cite this version:}

Don Passey, Gavin Hawkins, Darren Clift. Fathers and Male Guardians Are Important Stakeholders in Children's Education: Do Lego Building and Scratch-like Programming Activities Hold a Key to Involving Them More?. 1st International Conference on Stakeholders and Information Technology in Education (SAITE), Jul 2016, Guimarães, Portugal. pp.3-15, 10.1007/978-3-319-54687-2_1 . hal01625394

\author{
HAL Id: hal-01625394 \\ https://hal.inria.fr/hal-01625394
}

Submitted on 27 Oct 2017

HAL is a multi-disciplinary open access archive for the deposit and dissemination of scientific research documents, whether they are published or not. The documents may come from teaching and research institutions in France or abroad, or from public or private research centers.
L'archive ouverte pluridisciplinaire HAL, est destinée au dépôt et à la diffusion de documents scientifiques de niveau recherche, publiés ou non, émanant des établissements d'enseignement et de recherche français ou étrangers, des laboratoires publics ou privés.

\section{(ㄷ)(i)}

Distributed under a Creative Commons Attribution| 4.0 International License 


\title{
Fathers and Male Guardians are Important Stakeholders in Children's Education: Do Lego Building and Scratch-Like Programming Activities Hold a Key to Involving Them More?
}

\author{
Don Passey ${ }^{1}$, Gavin Hawkins ${ }^{2}$, and Darren Clift $^{2}$ \\ ${ }^{1}$ Centre for Technology Enhanced Learning, Department of Educational Research, Lancaster \\ University, UK, d.passeyel ancaster.ac.uk \\ ${ }^{2}$ Learning Technologies, Directorate of Education, Wolverhampton City Council, UK \\ \{ghawkins, dclift\}@cloudw.co.uk
}

\begin{abstract}
Previous research indicates positive influences on engagement, expectation and outcomes of learning when fathers and male guardians support and work with their children. In primary school settings, fathers and male guardians are less frequently seen to be involved in educational, school-based discussions and activities. The research reported in this paper indicates how a contemporary project is positively supporting father and male guardian involvement with their children, using technologies (Lego Technics Mindstorms and Scratch-like programming) as an important medium, where building and programming enable shared and collaborative learning. The findings highlight important ways in which this project is enabling this shared activity learning, through intergenerational learning practices. Clear implications for wider national and international development are raised. Recommendations are offered.
\end{abstract}

Keywords. Fathers/male guardians $\cdot$ learning with children $\cdot$ collaborative activities $\cdot$ intergenerational learning $\cdot$ primary school development.

\section{Introduction}

This paper explores the role of activities that support learning, where parents and guardians can work with their children through collaborative endeavour using technologies. Technology can play an important part in such activities; it can provide a medium where children and their parents and guardians can work together, where they can share how they are working as well as working collaboratively on the outcomes of their working. This paper focuses on collaborative endeavours using technologies at primary school level (where children are between 5 and 11 years of age). In this school sector, it is recognised in a number of countries that parents associate with their children's schools often; but mothers and female guardians are more frequently seen by schools coming in to work with their children, talking to their children immediately after school, and coming into school to discuss their progress. In 
a study in the United States (US), for example, Rimm-Kaufmann and Zang [1] found that in a sample of parents and guardians from a low-income population, about half of the fathers or male guardians had no contact with the teachers of their children in nursery schools, and only one in ten fathers or male guardians communicated with their child's infant school.

In this paper, we look at a project that has been run in three primary schools in a local authority in England; the project has sought to bring fathers and male guardians into school to work with their children, using technologies as a medium through which shared and collaborative learning can occur. In the project described, a case study has been used to look at activities in two different sites, and identifies outcomes arising. The findings indicate that this form of activity should be considered for wider practice, both to support the current curriculum that is stipulated in England, but also to potentially support engagement and learning between fathers and male guardians and their children more widely internationally.

\section{Roles of Parents and Guardians (Particularly Males) in Children's Learning}

Parents and guardians contribute to their children's learning, as recognised and measured in a number of past research studies. For example, as Bransford, Brown and Cocking [2] stated in their wide review of school-based learning and effective learning practices in the US: "Parents are especially good at helping their children make connections" (p.153). The authors suggested that parents and guardians are not only in a position to support their children, but may have important insights and personal knowledge that allow their children to see how to make learning connections, with other contexts and other ideas and knowledge. Desforges and Abouchaar [3], from their review of research findings in this field stated that: "parental involvement in the form of 'at-home good parenting' has a significant positive effect on children's achievement" (p.4). They concluded that: "In the primary age range the impact caused by different levels of parental involvement is much bigger than differences associated with variations in the quality of schools" (pp.4-5). In a later review of research on this topic, Harris and Goodall stated [4] that:

"Parental engagement is a powerful lever for raising achievement in schools. Where parents and teachers work together to improve learning, the gains in achievement are significant. Parents have the greatest influence on the achievement of young people through supporting their learning in the home rather than supporting activities in the school. It is their support of learning within the home environment that makes the maximum difference to achievement." (p.5)

These authors pointed to the need for forms of interactions between parents and children's learning to be as direct as possible if impact is to arise. In this context, in enabling direct interaction, technologies have a clear and already recognised part to play. But educational engagement of children that will affect their resultant outcomes must go beyond merely having access to technologies, or selecting resources, or using 
resources that are designed in particular ways, or depending on teachers choosing pedagogies to match learning approaches (as argued and discussed in McFarlane [5], for example). Key influences that bring about wider engagement and enhanced outcomes are socially driven - for example, parents encouraging children by taking note of their work and positively praising them, being present in environments where children's work is seen to be valued, asking questions about their work, or discussing with other children who take interest in their work and take pleasure in their findings (as discussed in government policy documents in England by the independent inspection service Ofsted [6], and by the government education department DfES [7]). In terms of supporting engagement that is educationally effective, parents and guardians can interact socially, while technologies support these social drivers through specific affordances that link and enhance these interactions. In the United Kingdom (UK), the potential for technologies to enhance home-based activities for learners and their parents and guardians has been highlighted by research over a number of years. Early studies explored the potential of the Internet and networking infrastructure, initially linking homes and schools, then using mobile technologies to allow interactions and resources to move via mobile technologies (laptops and palmtops) between schools and homes (described in Passey et al. [8, 9]; Kirkwood [10]; Passey [11, 12, 13]).

In terms of measuring the impact of home-based engagement on children's learning, Somekh et al. [14] explored differences in national test results in 28 schools in England, all supported with high levels of information and communication technologies (ICT), over a 4-year period, comparing them to a group and to national test averages. The researchers reported that while the Test Bed primary schools "were performing less well than matched comparator schools on a range of key performance measures: Key Stage 2 [age 7 to 11 years] English, mathematics, science and the APS [average points score] per institution" (p.8), that by the end of the project, the shift over the 4-year period from 2002 to 2006 was, for mathematics, $64 \%$ to $75 \%$ compared to $74 \%$ to $73 \%$ for the comparator schools.

Watson and Watson [15], in 2011, reported that technologically-based resources can afford choice and self-pacing for learners, indicating that resources can provide opportunities for children to work in locations remote from classrooms and schools. However, the role of parenting itself is clear from the results of other studies. Kiernan and Mensah [16] studied 5,462 children, who were assessed at age 5 years, and with mothers interviewed at periodic intervals. They found that: "children from poor families and those with lower levels of family resources who experienced more positive parenting were more likely to do well in school" (pp.327-328). Using technologies to support engagement with children's learning needs, therefore, to support and work with effective practices of parent and guardian engagement as well as offering activities that can provide learning support.

Existing research evidence indicates that enhancing parental and guardian engagement in learning practices can enable children to gain from parents' and guardians' interests. They can see and use role models of their parents' and guardians' practices, enabling children to more positively develop their own longer-term practices. As a Big Lottery Fund report [17] on out-of-school-hours learning states with regard to community-linked projects, these: "can help young people to develop their skills, and increase parental involvement" (p.46). But, as Byron [18] and 
Plowman, McPake and Stephen [19]) have pointed out, there is a need to consider the developing social needs and shifting social relationships of young people over time. How technologies support parental engagement and interactions for home and out-ofhours learning contexts of 5 year old children and of 12 year old children should consider their potentially different stages of social development and social relationships with parents and guardians.

In terms of fathers and male guardians, rather than parents and guardians as a whole, Cullen, Cullen, Band, Davis and Lindsay [20], in a study investigating Parent Support Advisor (PSA) pilots in 15 local authorities (LAs) in England indicated limited involvement with fathers in support of their children's learning and learning engagement in homes (as well as limitations in terms of planning for such involvement). Previous studies have shown that father and male guardian interest, high but reasonable expectations of their children, and direct involvement with their children's learning, are all associated with higher levels of test results, better progress in school and more positive attitudes towards future education (see Goldman [21]). The ways that fathers and male guardians can influence their children's learning (and how in some studies this can affect boys rather than girls, and vice versa) is discussed in greater depth in a review by the Fatherhood Institute [22]. However, other studies have pointed to the fact that low levels of father and male guardian involvement (especially during school time) may be linked to working practices, if fathers and male guardians have commitments at those certain times of the day (Peters, Seeds, Goldstein and Coleman [23]).

\section{The Lego Build and Scratch-Like Programming Project}

While Furlong and Davies [24] analysed the different ways that parents and guardians could work with their children, this activity has taken a project-based approach within the school setting. Project-based activities have been deployed in primary schools to support interactions between parents and guardians and their children, although the range of these activities that involve uses of technologies, as shown by a recent review [25], is much more limited than are the levels of many other forms of resources accessible to learners. The project that is the focus of the research reported in this paper was developed and run by Wolverhampton City Council in 2015 and 2016. Run in a number of schools, the project lasts for 3 to 5 weeks, with each weekly session being some one-and-a-half to two hours in length. The schools identified already had an interest in parental engagement and had previously undertaken programmes focused on improving parental understanding and involvement in basic skills (phonetic understanding, reading with their children, calculation processes, etc.). The senior leadership teams, within the schools concerned, saw the potential to extend existing programmes to include elements of computer science and also offer $21^{\text {st }}$ century skills to parents and guardians.

The schools are within economically deprived areas of the city, with high levels of unemployment, low levels of adult academic achievement and high mobility (including an above average intake from 'New Arrivals' and families with 'English as an Additional Language'). A significant driver for the schools concerned was to 
ensure that the programme could be accessed by families newly arrived in England and in turn increase access to the school and to educational skills for those families.

In one school (School A), four weekly sessions each 2 hours in length, involved fathers and male guardians with their children:

- Building a robot in week 1. Lego Technics (Mindstorms) was used for building the robot, as no explanation was needed for children when they started to use this technology.

- Programming the robot in week 2. Scratch-like programs were used for the programming.

- Creating a course and programming the robot to navigate it in week 3 .

- Racing their robots on a track, observed by other children and teachers in the school, with time to discuss what they had done in week 4 .

In another school (School B), the project ran over 3 weeks, each session being one-and-three-quarter hours in length. The focus and the expected outcomes of each of these sessions are shown in Table 1.

Table 1. Project content and expected outcomes in School B.

\begin{tabular}{|c|c|c|}
\hline Week & Content & Expected outcomes \\
\hline 1 & $\begin{array}{l}\text { Introductions } \\
\text { Initial outline of the project } \\
\text { Children and parents/guardians work on } \\
\text { the initial build of the basic robot } \\
\text { - Build guides are provided } \\
\text { - Photograph the process at each stage } \\
\text { - Staff to provide support and advice }\end{array}$ & $\begin{array}{l}\text { Parents/guardians and children work } \\
\text { together to build the initial robot } \\
\text { - Following instructions } \\
\text { - Solving any problems or issues } \\
\text { - Talking and evaluating their } \\
\text { models } \\
\text { - Recording of the process }\end{array}$ \\
\hline 2 & $\begin{array}{l}\text { Programming } \\
\text { Using the model built last week, begin to } \\
\text { experiment with the programming } \\
\text { application } \\
\text { Key commands should be } \\
\text { - Directions } \\
\text { - Distances } \\
\text { - Loop statements } \\
\text { - Develop single commands into } \\
\text { algorithms }\end{array}$ & $\begin{array}{l}\text { This session will involve lots of trial } \\
\text { and error as each pairing develop } \\
\text { instructions intended to control their } \\
\text { robot } \\
\text { Particular outcomes should be } \\
\text { - Fewest commands } \\
\text { - Shortest routes } \\
\text { - Algorithms which loop } \\
\text { - Saved sequences } \\
\text { Each pair will be encouraged to film } \\
\text { their robot's final program }\end{array}$ \\
\hline 3 & $\begin{array}{l}\text { 'Top Gear Pointless Challenge' } \\
\text { A series of challenges will be set up in } \\
\text { order to program and control the model } \\
\text { around a specific course } \\
\text { Navigating around the course will require } \\
\text { accurate algorithms and 'points' will be } \\
\text { awarded and deducted for speed and } \\
\text { accuracy }\end{array}$ & $\begin{array}{l}\text { Apply previous learning in order to } \\
\text { solve a range of challenges } \\
\text { - Problem solving skills } \\
\text { - Speaking and listening skills } \\
\text { - Accurate computer programming } \\
\text { and measuring of time, distance } \\
\text { and speed }\end{array}$ \\
\hline
\end{tabular}


The technologies involved in the project were LEGO Education Mindstorms EV3 and the associated LEGO Education app. The EV3 equipment allows for a programmable module to be built into a range of models designed to undertake specific tasks. It was decided to use $L E G O$ products as the assembly techniques of $L E G O$ are relatively simple and the equipment is designed to involve two people within the build and programming processes. Furthermore, full instructions are provided by $L E G O$ Education which encourage discussion and problem-solving during both the build and programming stages of the activity.

The Learning Technologies Team provided both the equipment and the iPads needed to undertake the tasks and were very much seen as facilitators during the project; helping with the build process and also offering initial and ongoing support during the programming process, although due to the nature of the icon-driven app, very little initial training was required.

Two new projects are planned to be delivered during the late spring and early summer of 2016, with a slightly amended model, designed to extend further some of the skills associated with three-dimensional (3D) design and printing. The project content and expected outcomes are shown in Table 2.

Table 2. Project content and expected outcomes in extension project.

\begin{tabular}{|c|c|c|}
\hline Session & Content & Expected Outcomes \\
\hline 1 & $\begin{array}{l}\text { Robotics } \\
\text { Introductions } \\
\text { Initial outline of project } \\
\text { Children and parents work on the } \\
\text { initial build of the basic robot: } \\
\text { - Build guides are provided } \\
\text { - Photographing the process } \\
\text { at each stage } \\
\text { - Staff to provide support and } \\
\text { advice }\end{array}$ & $\begin{array}{l}\text { Parents and children work together to build } \\
\text { the initial robot } \\
\text { Following instructions: } \\
\text { - Solving any problems or issues } \\
\text { - Talking about and evaluating their } \\
\text { models } \\
\text { - Recording of the process }\end{array}$ \\
\hline 2 & $\begin{array}{l}\text { Robotics - Programming } \\
\text { Using the model built last week, } \\
\text { begin to experiment with the } \\
\text { programming application. Key } \\
\text { commands should be: } \\
\text { - Directions } \\
\text { - Distances } \\
\text { - Loop statements } \\
\text { - Develop single commands } \\
\text { into algorithms }\end{array}$ & $\begin{array}{l}\text { This session will involve lots of trial and error } \\
\text { as each pairing develops instructions intended } \\
\text { to control their robot. Particular outcomes } \\
\text { should be: } \\
\text { - Fewest commands } \\
\text { - Shortest routes } \\
\text { - Algorithms which loop } \\
\text { - Saved sequences } \\
\text { Each pair will be encouraged to film their } \\
\text { robot's final program }\end{array}$ \\
\hline 3 & $\begin{array}{l}\text { Robotics - "Top Gear Pointless } \\
\text { Challenge" } \\
\text { A series of challenges will be set } \\
\text { up in order to programme and } \\
\text { control the model around a specific } \\
\text { course. Navigating around the } \\
\text { course will require accurate } \\
\text { algorithms and "points" will be } \\
\text { awarded and deducted for speed } \\
\text { and accuracy }\end{array}$ & $\begin{array}{l}\text { Apply previous learning in order to solve a } \\
\text { range of challenges: } \\
\text { - Problem solving skills } \\
\text { - Speaking and listening skills } \\
\text { - Accurate computer programming and } \\
\text { measuring of time, distance and speed }\end{array}$ \\
\hline
\end{tabular}




\begin{tabular}{|c|c|c|}
\hline Session & Content & Expected Outcomes \\
\hline 4 & $\begin{array}{l}\text { 3D Design - Sketch Up } \\
\text { Use of Google Sketch Up to produce a } \\
\text { 3D design in preparation for a 3D } \\
\text { model. The design could be for } \\
\text { something at home or a modification } \\
\text { to their robot or an artefact relating to } \\
\text { a school topic or project }\end{array}$ & $\begin{array}{l}\text { 3D design and online modelling skills: } \\
\text { - Precise measurements } \\
\text { - Visualising models } \\
\text { - Problem solving and speaking and } \\
\text { - listening skills } \\
\text { - Software skills (rotation, reflection, } \\
\text { perspective, etc.) }\end{array}$ \\
\hline 5 & $\begin{array}{l}\text { 3D Printing - Makerbots } \\
\text { Using the activity from last week, the } \\
\text { designs will be 3D printed in order } \\
\text { that the children can take them home. } \\
\text { Designs will need to be evaluated in } \\
\text { order that they can be printed, e.g. all } \\
\text { points must meet, no free-standing } \\
\text { parts, etc. }\end{array}$ & $\begin{array}{l}\text { The 3D printers will accurately print the } \\
\text { model as designed so each pair will need } \\
\text { to spend time discussing the integrity of } \\
\text { their model to ensure that the printer can } \\
\text { build up the model in layers: } \\
\text { - Visualisation skills } \\
\text { - Problem solving } \\
\text { - Editing and correcting issues as } \\
\text { they arise during the process } \\
\text { - Personal resilience }\end{array}$ \\
\hline
\end{tabular}

\section{Methodological Approaches and Methods}

The research adopted a case study approach. As Yin [26] says, "case studies are the preferred method when (a) "how" or "why" questions are being posed, (b) the investigator has little control over events, and (c) the focus is on a contemporary phenomenon within a real-life context" (p.2). This was exactly the situation the researchers confronted: they wanted to know how this project might be working and why it might be successful or adopted elsewhere; they did not want to intervene within the project activities as it was felt that these should be directed by the children working with their parent or guardian; and the project was contemporary in nature within a real-life school activity context.

The research questions that were identified at the outset were:

- How is this project working for children and their parents or guardians?

- What factors might suggest it could be adopted successfully elsewhere?

- How did children work with their parents or guardians?

- How did the activity fit within a school-based context?

Within this case study, three sites were involved, but the methods deployed to gather evidence in each case were similar. Evidence was gathered through:

- Documentary records of the project run in each case.

- Reflections by project staff involved in each case.

- Discussions with teachers, parents and guardians and children in each case.

- Observations in one case.

- Video reflections from both parents and children. 


\section{Findings from a Multiple Case Study}

In School A, four fathers and male guardians were involved in the four-week activity; in three cases, the fathers and male guardians worked with their sons, and in one case with a daughter. The four fathers and guardians came from different cultural and employment backgrounds. One father was from the Middle East with an engineering background, and three fathers and guardians were from the local area (with White British cultural backgrounds). The children were of different ages; the son of the Middle Eastern father was 7 years of age, while the other children were 10 years of age.

The staff running the project, reflecting on the outcomes from across the four weeks, reported that in week 1, fathers and male guardians tended to lead on the build activity, discussing this with their children. In week 2 , however, children tended to lead on the programming, while in week 3 both parties tended to be involved equally. Discussion generally between children and their fathers or guardians was found to be on task throughout these sessions.

Observation of the activity in week 4 showed that fathers and male guardians and children were working positively together. Early in the session, fathers and male guardians marked out the track that would be used for the race. The children tended to start on the programming, taking particular care with the programming needed to move the robots forward particular distances and to move them in different directions - using estimations from their previous trial experiences, both in terms of distance of travel and of angles of change of direction, using trial and error to amend and revise these details in other cases, and adjusting their robots until their movements were matched to their requirements. The ways in which the children and parents or guardians worked together differed in some respects. In one case, the father/guardian looked at instructions for the programming, while the child did the programming. In another case, the father/guardian did the programming, and in this latter case, the child had showed the father/guardian how to do the programming the previous week. He stated that he had had no previous experience with programming until he encountered it in this project; additionally, he indicated that he enjoyed the opportunity to engage with this form of activity, however.

Discussions with the fathers and male guardians highlighted how the form of the activity had engaged them positively in working with their children and in coming into the school. One father described how he remembered using Big Track in the past, when he was at school. He remembered that buttons needed to be pushed a number of times to direct a robot to move it forward a certain distance. He indicated how he had used this past experience in the current context, and how he had started to apply his experience to the programming he had undertaken the previous week. Other fathers also indicated how their previous experiences and interests had affected their engagement with this project. One parent said that he enjoyed activities that involved building, so had come along as his son also enjoyed this form of activity. Another father indicated how he had a long history of building, using Meccano and Lego. He said that this, coupled with a personal invitation from a teacher, had influenced his decision to come along. Another father indicated how he felt the activity would enable him to spend time working together with his child. Evidence from these fathers 
and male guardians indicated that these parents were more willing to participate in these school activities, and they referred to the project as a catalyst.

Since this initial project was completed, two further cohorts of parents and children in this school requested to be involved and they formed cohorts for revised projects (outlined in Table 2 above). The school also identified funding to establish a LEGO Innovation Centre, which will be used both within curriculum time to support lesson-based activities, but will also be available for 'family learning' and extracurricular activities. An additional by-product will be the availability for use of the Centre for staff professional development (within the school and more widely, subregionally).

In a second school, School B, five children were involved; three fathers and male guardians worked with their children (one girl and two boys), while two mothers and female guardians worked with their children (one boy and one girl). As in the case of School A, teachers had specifically targeted these parents and guardians, as they were seen less in the school than other parents and guardians.

In this school, the project staff observed a high level of engagement of both parents and guardians and children. Again, children and their parents or guardians tended to work collaboratively by using their respective strengths and previous experiences. Overall, it was recognised that those who were strong builders were not the strong programmers. Interestingly, the strong builders tended to be the parents and guardians, while the strong programmers tended to be the children. Clearly this pairing provided an ideal grouping for shared and collaborative endeavour. It was also reported that in this school (School B) the pairs had managed to get further with the programming, while children were less successful and less quick in School A. It was felt that part of the reason for this might have been due to changing to use of iPads in School B, allowing Bluetooth connectivity to be used to support more rapid testing of the effects of revised programming. With Bluetooth, the effects of programming could be seen more quickly. Trial and error, therefore, could be used more effectively, with less time happening between each successive trial.

Since the project, the school (School B) has gained from increased involvement from the parents and guardians. This is explained by school staff, both in terms of increased confidence when talking with staff in school, and in terms of greater comfort arising from their beliefs that the school values their involvement in their children's education. In addition, the school has seen the benefit of 'family learning' activities and is planning further projects and sourcing funding to develop a Family Learning Centre with associated resources and staffing.

\section{Discussion}

This project meets some the requirements of the current national curriculum for computing in England [27]. Indeed, the role of computing in developing creativity and problem-solving skills is not only highlighted as needs within that national curriculum, but is also highlighted by Lego as outcomes that can arise when children use these technologies [28]. 
However, this project goes beyond meeting the needs of a national curriculum, or even the needs for supporting the development of creativity and problem solving. It does this by adding an important social dimension - enabling fathers and guardians to work with their children in ways that both parties are contributing to a collaborative endeavour. It is not necessarily possible for the children or their fathers and guardians to know exactly which elements they contributed to the final solution; but they can be proud of the fact that they have both contributed, perhaps children more on the programming side and fathers and guardians more on the build side.

From a school point of view, parents and guardians they see less in the school are encouraged through this activity to attend, and to work with their children. This builds their relationships and options for further participation.

An essential bi-product of the project has been the recognition of the importance of educational skills beyond those traditionally associated with parents and children working together (reading, learning spelling-lists, phonic practice, traditional homework activities, etc.). This is important as it heightens the awareness of the 'softer skills' of problem-solving, collaboration and discussion, rather than just the completion of a task set by the child's teacher. It follows, therefore, that parents and children increasingly see the value of such skills and are more often able to apply them to their more traditional homework activities.

Clearly, there is a requirement for schools to make an initial investment in equipment and staff training; however, it is clear that the initial financial investment can reap significant returns, both from an engagement perspective but also from an increase in attainment within the computing curriculum. Clearly, additional research will need to focus on broader attainment measures.

\section{Conclusions, Implications and Recommendations}

In terms of the research questions highlighted at the outset:

- How is this project working for children and their parents or guardians? Evidence indicates that this was a successful project: children worked positively and were engaged with their parents or guardians; they discussed and worked together to develop a collaborative outcome; they all achieved success in building and programming; they developed skills that met the needs of the national curriculum; and they developed practices that they could adopt elsewhere, including at home.

- What factors might suggest it could be adopted successfully elsewhere? The children and parents and guardians in these schools came from what can be considered to be 'ordinary' backgrounds. If this activity works in this context, then it may well work in other contexts. Parents and guardians who were targeted did come into school, they worked with their children, sharing their skills and understanding, and contributed positively to the outcomes.

- How did children work with their parents or guardians? Children worked positively and were engaged with their parents or guardians; they discussed and worked together to develop a collaborative outcome; they contributed particularly in terms of programming; they developed skills in this respect 
that met the needs of the national curriculum; and they used creative and problem-solving skills to address challenges that they met.

- How did the activity fit within a school-based context? In terms of the school-based context, this project worked positively. Parents and guardians were encouraged to come into school, and the school could look to develop participation with these parents and guardians beyond this activity.

There are clear implications:

- Schools need to recruit cohorts and could, in some circumstances, target particular ethnic groups, age groups, socio-economic groups, etc.

- Schools need to invest in both equipment and staff time (or use a local support team with sufficient resources to deliver the projects - as in the case of the Learning Technologies Team in Wolverhampton).

Recommendations for policy, practice and research are:

- For policy, evidence of the impact of parental engagement on children's learning is clearly argued; therefore, funding should be made available for schools to initiate such schemes.

- Greater importance should be placed on the 'softer skills' of collaboration, problem-solving and resilience within curricular contexts.

- There should be formal accreditation for both children and parents who complete such projects and also for schools who are willing to commit to a culture of family learning.

- For practice, there should be greater opportunities for parents to become involved in their children's learning within the school day, for example, with mathematics, reading, science days or lessons, where parents are encouraged to work alongside their children. Too often parents only attend school during curriculum time for celebration events rather than to be involved in the processes leading to that celebration.

- Programmes focusing on skills deemed to be essential for employment within shortage areas within localities, for example, engineering and computing skills, should be developed further.

- For research, there should be opportunities for a wider research agenda to investigate regional variations, for example, across the UK and Europe, focusing more specifically on attainment outcomes.

- Opportunities focusing on the contribution of softer skills to academic outcomes.

- Future employment opportunities for parents undertaking this form of project and other family learning experiences.

- The impact of LEGO Educational and Scratch-like activities within a national curriculum context.

Acknowledgements. The authors would like to thank: the children, parents and staff of Eastfield and Bantock Primary Schools for their enthusiasm and willingness to be involved; LEGO Education UK for providing advice, support and additional 
resources; and Wolverhampton City Council's East Park Action Group for funding the project reported here and for providing administrative support.

\section{References}

1. Rimm-Kaufmann, S.E., Zhang, Y.B.: Father-school communication in preschool and kindergarten. School Psychology Review. 34(3), 287-308 (2005)

2. Bransford, J.D., Brown, A.L., Cocking, R.R. (eds.): How People Learn: Brain, Mind, Experience, and School. National Academy Press, Washington, DC (2000)

3. Desforges, C., Abouchaar, A.: The impact of parental involvement, parental support and family education on pupil achievement and adjustment: A literature review. Report Number 433. Department of Education and Skills, London (2003)

4. Harris, A., Goodall, J.: Engaging Parents in Raising Achievement: Do Parents Know They Matter? Research Report DCSF-RW004. DCSF, London (2007)

5. McFarlane, A.: Learners, learning and new technologies. Educational Media International. 40(3), 219-227 (2003)

6. Office for Standards in Education: Family learning: a survey of current practice. Ofsted, London (2000)

7. Her Majesty's Government Green Paper: Every Child Matters. The Stationery Office, Norwich (2003)

8. Passey, D., Forsyth, K., Hutchison, D., Scott, A., Williams, N.: Superhighways Evaluation - Group D - Home-School Links: Final Report. NCET, Coventry (1997)

9. Passey, D., Forsyth, K., Hutchison, D., Scott, A., Williams, N.: Summary: Group D Home-School Links. In Scrimshaw, P. (ed.) Preparing for the Information Age: Synoptic Report of the Education Departments' Superhighways Initiative. DfEE, London, WO, Cardiff, DENI, Belfast, The Scottish Office, Edinburgh (1997)

10. Kirkwood, A.: Learning at home with information and communication technologies. Distance Education. 21(2), 248-259 (2000)

11. Passey, D.: Developing Home-School ICT uses: Challenging values and thinking. In Connected Thinking: Report of a seminar organised by the Society of Education Officers. Society of Education Officers, London (2000)

12. Passey, D.: Developing home-school links: Implications for learners, learning, and learning support. In Taylor, H., Hogenbirk, P. (eds.) Information and communication technologies in education: the school of the future. Kluwer Academic Publishers, Boston, MA (2000)

13. Passey, D.: Developing Teaching Strategies for Distance (Out-of-School) Learning in Primary and Secondary Schools. Educational Multimedia International. March issue (2000)

14. Somekh, B., Underwood, J., Convery, A., Dillon, G., Jarvis, J., Lewin, C., Mavers, D., Saxon, D., Sing, S., Steadman, S., Twining, P., Woodrow, D.: Evaluation of the ICT Test Bed project Final Report June 2007. Becta, Coventry (2007)

15. Watson, S.L., Watson, W.R.: The Role of Technology and Computer-Based Instruction in a Disadvantaged Alternative School's Culture of Learning. Computers in the Schools. 28(1), 39-55 (2011)

16. Kiernan, K.E., Mensah, F.K.: Poverty, family resources and children's early educational attainment: the mediating role of parenting. British Educational Research Journal. 37(2), 317-336 (2011)

17. Big Lottery Fund: Building the future of learning: A guide to sustaining out of hours learning. Big Lottery, London (n.d.) 
18. Department for Children, Schools and Families: Safer Children in a Digital World: The Report of the Byron Review. DCSF, London (2008)

19. Plowman, L., McPake, J., Stephen, C.: Just picking it up? Young children learning with technology at home. Cambridge Journal of Education. 38(3), 303-319 (2008)

20. Cullen, S.M., Cullen, M.A., Band, S., Davis, L., Lindsay, G.: Supporting fathers to engage with their children's learning and education: an under-developed aspect of the Parent Support Adviser pilot. British Educational Research Journal. 37(3), 485-500 (2011)

21. Goldman, R.: Fathers' Involvement in their Children's Education. National Family and Parenting Institute, London (2005)

22. The Fatherhood Institute: Fathers' impact on their children's learning and achievement. Fatherhood Institute, Abergavenny (2010)

23. Peters, M., Seeds, K., Goldstein, A., Coleman, N.: Parental Involvement in Children's Education. Research Report DCSF RR034. DCSF, London (2008)

24. Furlong, A., Davies, C.: Young people, new technologies and learning at home: taking context seriously. Oxford Review of Education. 38(1), 45-62 (2011)

25. Passey, D.: Inclusive technology enhanced learning: Overcoming Cognitive, Physical, Emotional and Geographic Challenges. Routledge, New York, NY (2013)

26. Yin, R.K.: Case Study Research: Design and Methods ( $4^{\text {th }}$. Ed.). Sage, Thousand Oaks, CA (2009)

27. DFE: Statutory guidance - National curriculum in England: computing programmes of study. DFE, London (2013). Accessed 5 January 2015 at: https://www.gov.uk/government/publications/national-curriculum-in-england-computingprogrammes-of-study/national-curriculum-in-england-computing-programmes-of-study

28. Gauntlett, D., Ackermann, E., Whitebread, D., Wolbers, T., Weckstrom, C., Thomsen, B.S. The Future of Learning. Lego Learning Institute, n.p. (n.d.) 